\title{
Carcinoembryonic Antigen as a Prognostic Factor in Colorectal Cancer with Liver Metastases
}

\author{
George E. McNally' ${ }^{1}$ David M. Lloyd ${ }^{2}$, Jorge P. Grondona ${ }^{3}$ \\ ${ }^{1}$ College of Medical and Dental Sciences, University of Birmingham, Birmingham, UK \\ ${ }^{2}$ Department of Hepatobiliary and Pancreatic Surgery, University Hospitals of Leicester, Leicester, UK \\ ${ }^{3}$ Department of Surgery, Centro Medico de San Isidro, Buenos Aires, Argentina \\ Email:gem060@bham.ac.uk,dmlloyd1@aol.com,jorgepablogrondona@gmail.com
}

Received 30 September 2015; accepted 2 November 2015; published 5 November 2015

Copyright (C) 2015 by authors and Scientific Research Publishing Inc.

This work is licensed under the Creative Commons Attribution International License (CC BY).

http://creativecommons.org/licenses/by/4.0/

(c) $\underset{\mathrm{EY}}{\text { (i) Open Access }}$

\begin{abstract}
Aim: The objective of this study was to investigate the prognostic value of serum carcinoembryonic antigen (CEA) level in colorectal cancer patients with liver metastases. The serum CEA level was recorded at the point of metastasis diagnosis, differing from the majority of literature looking at preoperative metastasectomy CEA level. Methods: From January 2010 to December 2014, 138 patients with a diagnosis of colorectal cancer and liver metastases were included in the study-population from Buenos Aires, Argentina. Patients with both resectable and unresectable liver metastases were followed up over a 4-year period. Kaplan Meier survival analysis was used to produce survival curves that were compared by log-rank test. Results: The overall survival for all patients studied with a CEA < $100 \mathrm{ng} / \mathrm{ml}$ was significantly longer compared to patients with CEA $\geq 100 \mathrm{ng} / \mathrm{mL}(\mathrm{p}<0.001)$. The 1-, $2-$, and 3-year overall survival rates for the whole cohort were $73.6,56.6$ and $53.8 \%$ respectively. For patients with unresectable metastases, a low CEA level $(<100 \mathrm{ng} / \mathrm{mL})$ was also associated with the increased overall survival $(p=0.036)$. Conclusions: In our patient cohort, this study indicated that a low CEA level $(<100 \mathrm{ng} / \mathrm{mL})$ measured at metastasis diagnosis was a good prognostic indicator for improving survival in patients with colorectal liver metastases. These findings highlight the importance of measuring serum CEA levels in this group of patients at the time of liver metastasis diagnosis.
\end{abstract}

\section{Keywords}

Carcinoembryonic Antigen (CEA), Colorectal Cancer Survival, Liver Metastasis, Postoperative Mortality 


\section{Introduction}

Colorectal carcinoma (CRC) is the commonest malignancy of the digestive tract and the third most common cancer in the Western world [1]. The most important risk factor is the age with disease rarely developing in people under the age of 40 . The majority of colorectal cancers develop sporadically, however family history of CRC in a first-degree relative confers a 2- to 3-fold increased risk of disease. Environmental risk factors include obesity, physical inactivity, low fibre diet and a high intake of red and processed meats.

The liver is the most common site for colorectal cancer metastases due to the enteric venous drainage via the portal circulation with up to 50\% of CRC patients developing liver metastases [2] [3]. Furthermore, the liver is the only site of metastasis in 35\% of cases [4]. Studies have shown that $10 \%-30 \%$ of patients with liver-limited colorectal metastases have potentially resectable disease at the point of detection and can be treated surgically aiming for improving prognosis and potential long-term cure [5]. The surgical removal of hepatic metastases has been shown to improve survival significantly, with reported 5-year survival rates of $30 \%-40 \%$. Recent advances in the surgical technique for partial hepatectomy, indications for liver resection, imaging modalities and perioperative care have increased the number of patients suitable for surgical resection and the overall safety of the procedure [6] [7].

Serum carcinoembryonic antigen (CEA) is widely accepted as a clinically significant prognostic indicator of recurrence and therapeutic benefit in colorectal cancer [8]-[10]. However, the prognostic value of CEA in colorectal cancer with liver metastasis is less well understood. Mann et al. demonstrated a benefit of low CEA levels $(<200 \mathrm{ng} / \mathrm{mL})$, reporting a 5-year survival of $48.9 \%$, compared to $0 \%$ for those patients with a CEA $\geq 200$ $\mathrm{ng} / \mathrm{mL}$ [11]. A meta-analysis showed that the low preoperative CEA level $(<50 \mathrm{ng} / \mathrm{ml})$ was associated with a significantly better survival time following liver metastasis resection [12]. A further meta-analysis used a cut-off value of $200 \mathrm{ng} / \mathrm{mL}$ to stratify the two groups and also demonstrated an improved survival time with a lower CEA level [13]. The literature also includes cut-off values of $20 \mathrm{ng} / \mathrm{mL}$ and $100 \mathrm{ng} / \mathrm{mL}$, highlighting the limitations of comparing these different studies [14]. It is important to acknowledge that other studies have failed to identify a significant survival disadvantage of a raised preoperative CEA level [15]-[18]. Therefore, the optimal cut-off point and its subsequent impact on prognosis remain uncertain.

The role of CEA as a prognostic factor for unresectable colorectal liver metastases is not well documented. Mitsuyama et al. investigated the clinical significance of serum CEA and CA19-9 levels in 40 patients with a diagnosis of unresectable liver metastases, reporting that both tumour markers were significant and independent predictors of poor survival [19]. Recent advancements in chemotherapy regimens have demonstrated survival benefits for patients with advanced colorectal cancer, including those with unresectable liver metastases. Therefore, the measurement of the serum CEA upon diagnosis of colorectal liver metastasis, whether hepatic resection or non-surgical management is considered, may provide important prognostic information and contribute to further advances in the therapeutic strategy of this common cancer.

Other prognostic factors for long-term survival have been identified previously for colorectal cancer patients with liver metastases. These include degree of primary tumour differentiation, resection margin, nodal involvement, tumour grade and size, number of liver metastases and resection of the liver metastases or not [13] [14]. Other serum tumour markers, including CA19-9 have been studied, as well as markers of proliferative activity (TK, TPS, TPA), however, CEA is the marker that most often used as a prognostic indicator [20].

The aim of this study is to investigate the prognostic value of serum CEA level at the point of metastasis diagnosis, in contrast to the previously well-documented CEA level at the time of metastasis surgery, termed preoperative CEA level. This could allow for an indication of survival time to be communicated to patients earlier in their disease process and could provide useful information to the clinician on future management options. It will also add to the limited literature on the use of CEA as a prognostic indicator in unresectable liver metastases. This study investigates both patients who underwent surgical resection of metastases, and also patients in which metastases were deemed unresectable and palliative measures were commenced.

\section{Patients and Methods}

A total of 138 patients with a diagnosis of colorectal cancer and liver metastases were entered into the Methepar database at the UNACIR HPB (Association of Hepatopancreatobiliary Surgery) centre in San Isidro, Provence of Buenos Aires, Argentina, since it was established in 2010. The database includes patients with liver metas- 
tases who underwent surgery and also patients with unresectable liver metastases. Of the 138 patients, a total of 32 patients were excluded from the study: 22 patients with a diagnosis of liver metastases prior to January 2010 or after December 2014 were excluded; 5 patients were excluded due to no baseline CEA value; 3 patients due to death from other causes; 2 due to insufficient data entry. Thus, data for 106 patients were included in this retrospective study and were made eligible for final analysis. Ethical approval was established for data entry into the Methepar database in 2010 by Professor Jorge Pablo Grondona, Director of UNACIR HPB, San Isidro, Argentina. All participants included in the database had given written informed consent, ensuring they fully understood the requirements of inclusion in the database.

Metastases were considered unresectable if extrahepatic disease existed, vascular invasion occurred or if the size and number of metastases were deemed too extensive to operate. Data for each patient were extracted from the database, to include age, gender, date of colorectal cancer diagnosis, metastasis diagnosis and whether this was synchronous or metachronous (more than three months between the two diagnoses). The serum CEA level at the time of metastasis diagnosis, the date of surgical resection and date of death or last follow-up was recorded for each patient, stating whether the patient remained disease free, the metastasis had progressed, or the metastasis had recurred following resection.

A cut-off value of $100 \mathrm{ng} / \mathrm{mL}$ for serum CEA level was used in consideration of the previous literature. Wang et al. used this value in a similar preoperative CEA study, as did Mitsuyama et al in a study looking at the use of CEA in a group of patients with unresectable disease [14] [19]. Other literature used cut-off values ranging from 20 to $200 \mathrm{ng} / \mathrm{mL}$, thus $100 \mathrm{ng} / \mathrm{mL}$ did not seem inappropriate in the context of this study [11]-[13] [21] [22].

\section{Statistical Analysis}

The statistical analysis was processed with SPSS 21 statistical software. Survival time was calculated from date of metastasis diagnosis to death or censored date. Survival was measured in months with the use of median values. Patients who died from colorectal cancer were treated as event observations, whereas patients who were alive at the point of last follow-up were treated as censored observations. The Kaplan-Meier method was used to produce survival curves, which were compared by the log-rank test. $\mathrm{p}<0.05$ was considered to be statistically significant.

\section{Results}

\subsection{Patient Demographics}

The study population included 58 men (54.7\%) and 48 women (45.3\%) shown in Table 1 . The median patient age was 63 years (range 35 - 90 years). Of the 106 patients, 51 underwent liver metastasis resection (48.1\%) and 55 patients did not receive surgical intervention (51.9\%). 34 patients (32.1\%) were given a synchronous diagnosis of colorectal cancer and liver metastases. A diagnosis was considered synchronous if both were diagnosed within a 3-month period. Death occurred in 49 patients (46.2\%), 42 patients were deemed disease free at the point of last follow-up (39.6\%) and 15 patients had persistent, progressive or recurrent disease (14.2\%). Raised serum CEA levels ( $\geq 100 \mathrm{ng} / \mathrm{mL}$ ) recorded at the point of metastasis diagnosis were observed in 42 patients (39.6\%) and 64 patients (60.4\%) had a low CEA level $(<100 \mathrm{ng} / \mathrm{mL})$. The overall survival for the whole population is depicted in Figure 1. The 1-, 2-, and 3-year overall survival rates were 73.6, 56.6 and 53.8\% respectively.

\subsection{Overall Survival for All Patients with CEA $<100$ and CEA $\geq 100 \mathrm{ng} / \mathrm{mL}$}

Figure 2 shows the overall survival for all patients with a CEA $\geq 100$ or CEA $<100 \mathrm{ng} / \mathrm{mL}$. For those patients with a CEA $<100 \mathrm{ng} / \mathrm{ml}$ the median survival was 33.0 months (95\% CI, 21.6 to 44.4). For patients with a CEA $\geq 100 \mathrm{ng} / \mathrm{ml}$, median survival was significantly less at 14.0 months (95\% CI, 11.8 to 16.2; $\mathrm{p}<0.001$ ).

\subsection{Overall Survival of Surgical Patients with CEA $<100$ and CEA $\geq 100 \mathrm{ng} / \mathrm{mL}$}

Figure 3 shows the overall survival of the surgical group based on CEA $<100$ or $\geq 100 \mathrm{ng} / \mathrm{mL}$ at the time of metastasis diagnosis. The results of this analysis show that there was not a significant difference in survival stratifying patients on the basis of CEA above or below 100 at the time of diagnosis of metastasis (Median survival CEA $<100$ ng/ml 22 months versus CEA $\geq 100$ ng/ml 29.5 months, $\mathrm{p}=0.562$ ). 
Table 1. Characteristics of patients with colorectal cancer and liver metastases.

\begin{tabular}{lcc}
\hline Characteristic & Frequency & Percentage (\%) \\
\hline Gender & 58 & 54.7 \\
Male & 48 & 45.3 \\
Female & & \\
Age & 43 & 40.6 \\
$<60$ & 63 & 59.4 \\
$\geq 60$ & & \\
CEA levels at metastasis diagnosis (ng/mL) & 64 & 60.4 \\
$<100$ & 42 & 39.6 \\
$\geq 100$ & & \\
Resection of liver metastases & 51 & 48.1 \\
Yes & 55 & 51.9 \\
No & & \\
Time of diagnosis of liver metastases & 34 & 32.1 \\
Synchronous & 72 & 67.9 \\
Metachronous & &
\end{tabular}

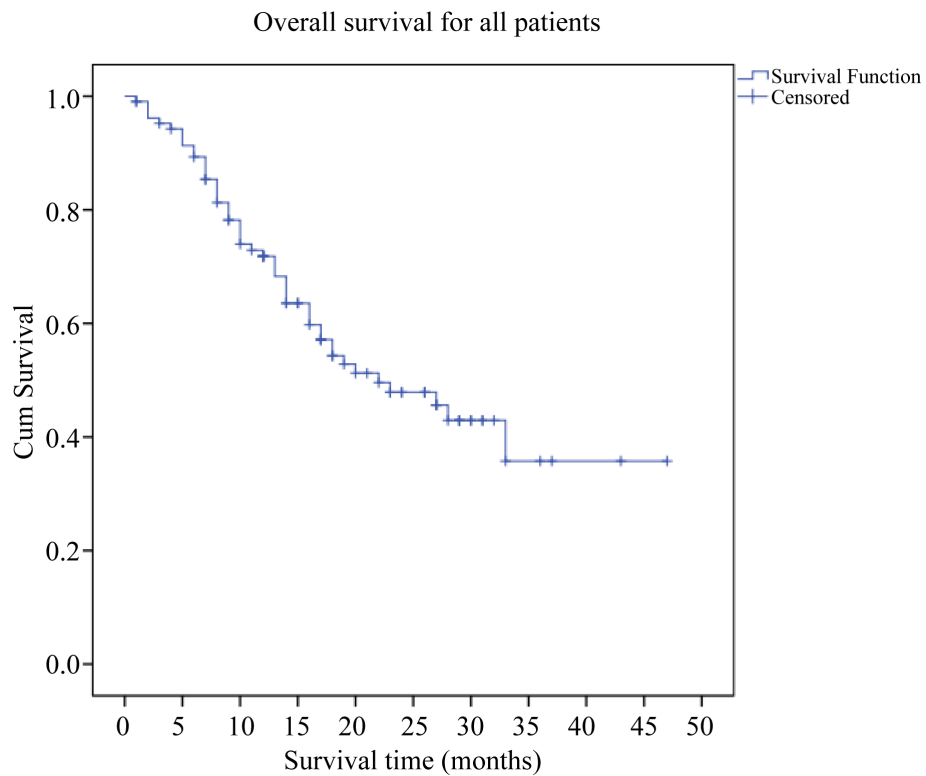

Figure 1. Overall survival curve for all patients.

\subsection{Overall Survival of Non-Surgical Patients with CEA $<100$ and CEA $\geq 100 \mathrm{ng} / \mathrm{mL}$}

Figure 4 shows that there was a significant difference in overall survival of non-surgical patients stratified on the basis of CEA $<100$ or $\geq 100 \mathrm{ng} / \mathrm{mL}$. The median survival for patients with a CEA $<100 \mathrm{ng} / \mathrm{mL}$ at diagnosis of metastasis was 14.0 months (95\% CI, 7.2 to 20.8), compared to a median survival of 9.0 months in patients with a CEA $\geq 100 \mathrm{ng} / \mathrm{mL}(95 \% \mathrm{CI}, 6.5$ to $11.5 ; \mathrm{p}=0.036)$. 
Overall survival for all patients with CEA $<100$ and CEA $\geq 100 \mathrm{ng} / \mathrm{mL}$

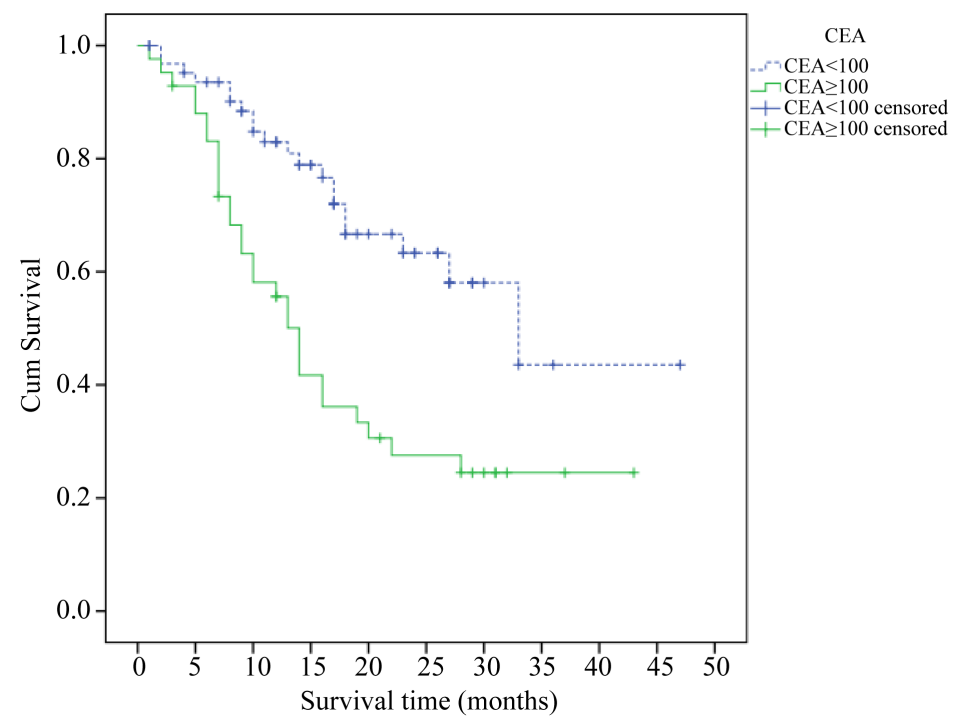

Figure 2. Overall survival for all patients with CEA $<100$ and CEA $\geq 100$ $\mathrm{ng} / \mathrm{mL}$.

Overall survival of surgical patients with CEA $<100$ and CEA $\geq 100 \mathrm{ng} / \mathrm{mL}$

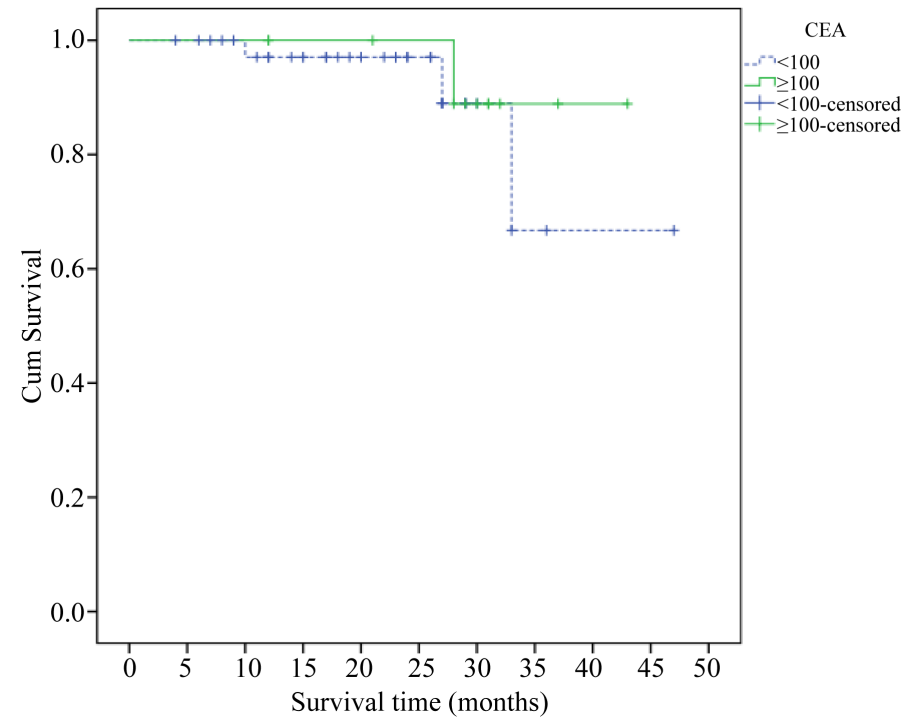

Figure 3. Overall survival for surgical patients with CEA $<100$ and $\mathrm{CEA} \geq 100 \mathrm{ng} / \mathrm{mL}$.

\subsection{Overall Survival of Surgical Versus Non-Surgical Patients}

Figure 5 shows the overall survival comparing patients who underwent metastasis resection versus patients who were managed medically. At the time of study analysis, $72.4 \%$ of surgically treated patients were still alive at 3 years, compared to $0 \%$ of non-surgical patients who were alive at 2 years $(\mathrm{p}<0.001)$.

\section{Discussion}

This study confirms that there is a significant difference in the survival of all patients with colorectal liver metastases when stratified for CEA levels (CEA $<100$ or $\geq 100 \mathrm{ng} / \mathrm{mL}$ ) taken at metastasis diagnosis. Much of the 
Overall survival of non-surgical patients with $\mathrm{CEA}<100$ and CEA $\geq 100 \mathrm{ng} / \mathrm{mL}$

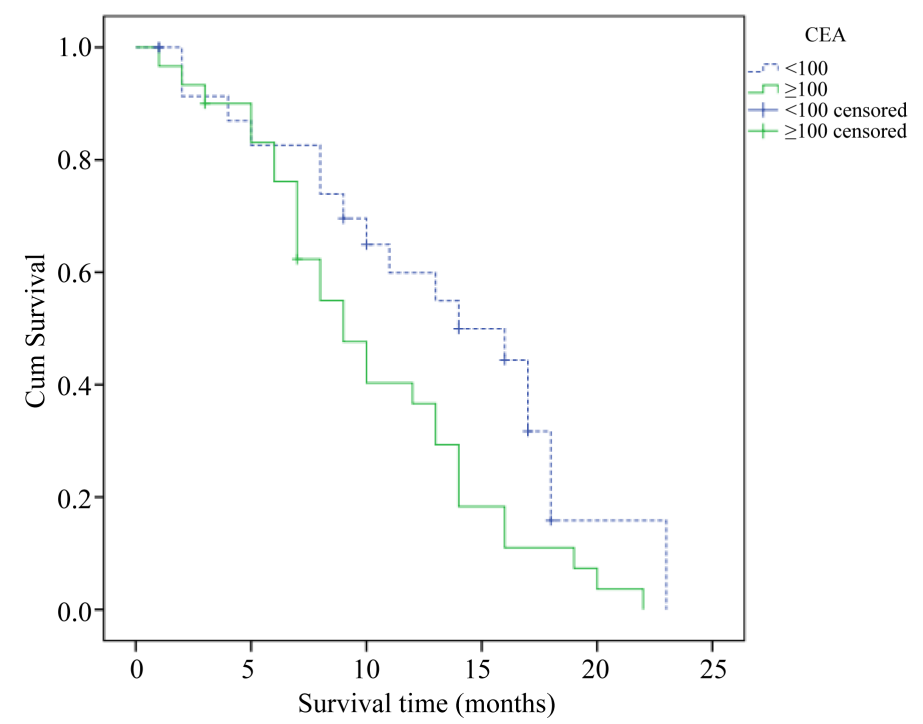

Figure 4. Overall survival for non-surgical patients with CEA $<100$ and CEA $\geq 100 \mathrm{ng} / \mathrm{mL}$.

Overall survival of surgical versus non-surgical patients

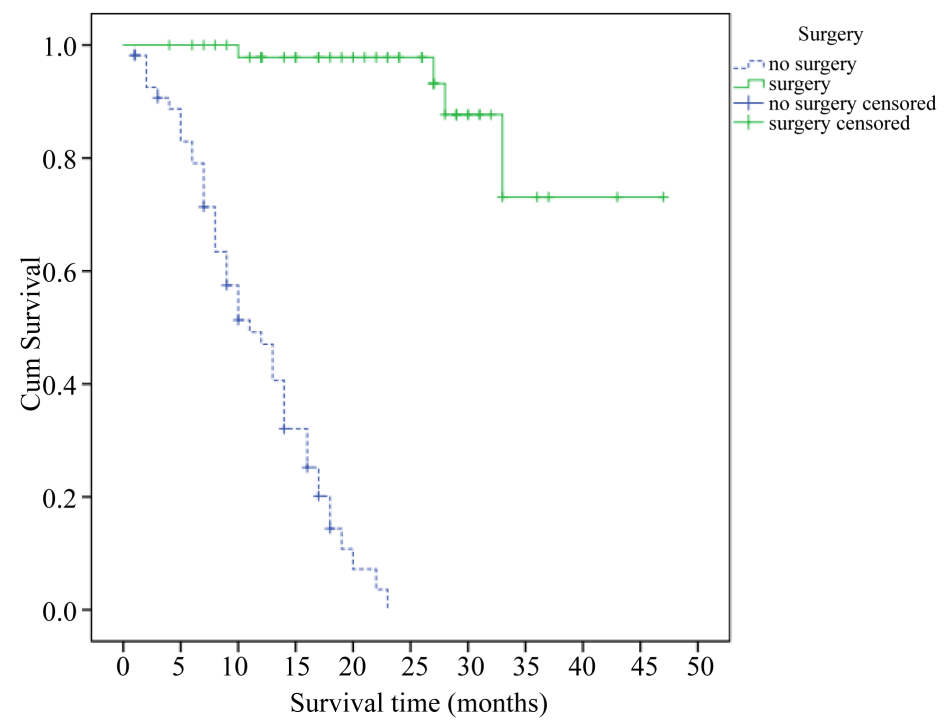

Figure 5. Overall survival of surgical vs non-surgical patients.

literature has previously studied preoperative CEA levels in patients undergoing liver resection. The primary finding of this study indicates that CEA measurement taken early in the disease process (at metastasis diagnosis) is predictive of prognosis. Measurement of CEA at metastasis diagnosis enables clinicians to communicate survival rates to patients at an earlier stage and will help guide appropriate future management.

This study is consistent with previously published literature reporting the benefits of surgical resection of liver metastases in patients with colorectal carcinoma. It supports the use of hepatic metastasectomy for increasing long-term survival and for providing a potential long-term cure [14]. Due to advances in the surgical technique, long-term survival is improving, with 5-year survival surpassing 50\% in recent studies [23]-[29].

However, there has been limited research into those patients in whom liver metastases are deemed unresectable. This study shows that those patients with unresectable liver metastases and a low CEA level $(<100$ 
$\mathrm{ng} / \mathrm{mL}$ ) at metastasis diagnosis are associated with a longer survival time. This observation adds to the limited research conducted in this area and supports the findings of Mitsuyama et al. [18]. In 2012, this group also used $100 \mathrm{ng} / \mathrm{mL}$ as the cut off value for CEA and found that CEA was an independent predictor of overall survival in patients with unresectable colorectal liver metastases [19]. This highlights the importance of measuring serum CEA at metastasis diagnosis even in patients in whom liver resection is deemed not possible. Clinical research has shown that the absolute level of this tumour marker is dependent on the tumour mass [30] [31]. Advances in chemotherapy regimes have provided this group of patients with significant survival benefits [19]. In our study, a median survival difference of 5 months was noted between subjects with a low and high CEA level, which proved to be statistically significant and may aid in improving the management and expectations of patients with unresectable liver metastases and a low CEA level.

Although, serum CEA level has value as a prognostic indicator for both resectable and unresectable colorectal liver metastases, it is important to include other prognostic indicators when assessing the overall survival of patients with hepatic metastatic colorectal carcinoma. The development and use of prognostic scoring systems has been controversial in previous literature, due to inconsistency in combining pre-operative factors. Meta-analysis performed by Spolverato et al. suggested they were unreliable in accurately determining prognosis [32]. In 1996, the first scoring system was described by Nordlinger et al. [33], in which one point was given to each of the following factors: age, size, stage of primary tumour, CEA level, resection margin, number of nodules and diseasefree interval. Later, a cohort of 1001 patients treated with resection of liver metastases was studied by Fong et al. [4]. They found that only 5 preoperative factors impacted significantly on prognosis, including a CEA level $\geq 200 \mathrm{ng} / \mathrm{mL}$, number of hepatic metastases $>1$, disease-free interval, nodal status of primary tumour and the size of the largest metastasis $>5 \mathrm{~cm}$ [4]. This scoring system has been used extensively, however, some groups confirm its validity, whilst others have brought into question its prognostic accuracy [11] [34]-[36]. Ultimately, the clinical value of these prognostic scoring systems remains uncertain. Nathan et al. postulated that this was due to an inability to account for the benefit of neoadjuvant chemotherapy, varying resection rates and difficulties in establishing consistent cut-off values for factors with continuous data, such as CEA level [37].

It may also be more appropriate to look at the CEA level dynamically, instead of using a single static CEA level. This would eliminate the problem of establishing a common cut-off value. For example, in surgically treated patients looking at the ratio of preoperative and postoperative CEA levels would allow for better understanding of the disease process [38]. Liska et al. found that the ratio of pre-operative to post-operative CEA level was statistically significant when predicting early recurrence. The use of CEA levels dynamically was also found to be an excellent prognostic indicator of disease-free interval and ultimately survival in patients with colorectal liver metastases [38]. Thus, a full understanding of the behaviour of tumour markers in the follow-up period could be an important indicator for survival and guide for subsequent therapy.

Although, serum CEA level measurements have demonstrated a prognostic importance, recent studies have investigated the measurement of tissue CEA levels concurrently. Park et al. measured tissue and serum CEA concentration after resection for colorectal liver metastases and demonstrated that CEA expression was an independent prognostic indictor of both overall survival and disease free survival [39]. In this study, patients with both raised serum and tissue CEA level were found to have a worse prognosis compared to patients who just had one CEA category elevated. This technique could help improve the accuracy and validity of using CEA as a prognostic marker.

\section{Conclusion}

In conclusion, this study shows that a low CEA level $(<100 \mathrm{ng} / \mathrm{mL})$ measured at metastasis diagnosis is a significant prognostic indicator of overall survival in patients with colorectal liver metastases. More specifically, in patients with unresectable disease, a CEA level $<100 \mathrm{ng} / \mathrm{mL}$ was found to have a statistically significant survival benefit. Measuring CEA at metastasis diagnosis has prognostic significance, enabling clinicians to counsel patients about survival rates at an earlier stage in the disease process, whilst also helping to guide the future management of patients with colorectal cancer liver metastases. This study adds to the earlier research into the use of tumour markers for predicting prognosis in this disease process.

\section{References}

[1] Haggar, F.A. and Boushey, R.P. (2009) Colorectal Cancer Epidemiology: Incidence, Mortality, Survival, and Risk 
Factors. Clinics in Colon and Rectal Surgery, 22, 191-197. http://dx.doi.org/10.1055/s-0029-1242458

[2] Khatri, V.P., et al. (2005) Extending the Frontiers of Surgical Therapy for Hepatic Colorectal Metastases: Is There A Limit? Journal of Clinical Oncology, 23, 8490-8499. http://dx.doi.org/10.1200/JCO.2004.00.6155

[3] Benson, A.B., et al. (2007) Epidemiology, Disease Progression, and Economic Burden of Colorectal Cancer. Journal of Managed Care Pharmacy, 13, S5-S18.

[4] Fong, Y., et al. (1999) Clinical Score for Predicting Recurrence after Hepatic Resection for Metastatic Colorectal Cancer: Analysis of 1001 Consecutive Cases. Annals of Surgery, 230, 209-321. http://dx.doi.org/10.1097/00000658-199909000-00004

[5] Rees, M., et al. (2008) Evaluation of Long-Term Survival after Hepatic Resection for Metastatic Colorectal Cancer: A Multifactorial Model of 929 Patients. Annals of Surgery, 247, 25-135. http://dx.doi.org/10.1097/sla.0b013e31815aa2c2

[6] Folprecht, G., et al. (2005) Neoadjuvant Treatment of Unresectable Colorectal Liver Metastases: Correlation between Tumour Response and Resection Rates. Annals of Oncology, 16, 13311-1319. http://dx.doi.org/10.1093/annonc/mdi246

[7] Chung, K.Y., et al. (2005) Antibody-Based Therapeutics for Colorectal Cancer. Oncologist, 10, 701-709. http://dx.doi.org/10.1634/theoncologist.10-9-701

[8] Wanebo, H.J., Rao, B., Pinsky, C.M., Hoffman, R.G., Stearns, M., Schwartz, M.K. and Oettgen, H.F. (1978) Preoperative Carcinoembryonic Antigen Level as a Prognostic Indicator in Colorectal Cancer. The New England Journal of Medicine, 299, 448-451. http://dx.doi.org/10.1056/NEJM197808312990904

[9] Moertel, C.G., O’Fallon, J.R., Go, V.L., O’Connell, M.J. and Thynne, G.S. (1986) The Preoperative Carcinoembryonic Antigen Test in the Diagnosis, Staging, and Prognosis of Colorectal Cancer. Cancer, 58, 603-610. http://dx.doi.org/10.1002/1097-0142(19860801)58:3<603::AID-CNCR2820580302>3.0.CO;2-K

[10] Zamcheck, N. (1975) The Present Status of CEA in Diagnosis, Prognosis, and Evaluation of Therapy. Cancer, 36, 2460-2468. http://dx.doi.org/10.1002/1097-0142(197512)36:6<2460::AID-CNCR2820360631>3.0.CO;2-6

[11] Mann, C.D., Metcalfe, M.S., Leopardi, L.N. and Maddern, G.J. (2004) The Clinical Risk Score: Emerging as a Reliable Preoperative Prognostic Index in Hepatectomy for Colorectal Metastases. Archives of Surgery, 139, 1168-1172. http://dx.doi.org/10.1001/archsurg.139.11.1168

[12] Abbas, S., Lam, V. and Hollands, M. (2011) Ten-Year Survival after Liver Esection for Colorectal Metastases: Systematic Review and Meta-Analysis. ISRN Oncology, 2011, Article ID: 763245. http://dx.doi.org/10.5402/2011/763245

[13] Kanas, G., Taylor, A., Primrose, J.N., Langeberg, W.J., Kelsh, M.A., Mowat, F.S., et al. (2012) Survival after Liver Resection in Metastatic Colorectal Cancer: Review and Meta-Analysis of Prognostic Factors. Clinical Epidemiology, 4, 283-301.

[14] Wang, Y., Liu, Y.F., Cheng, Y., Yi, D.H., Li, P., Song, W.Q., Fu, D.Z. and Wang, X. (2010) Prognosis of Colorectal Cancer with Liver Metastasis: Value of a Prognostic Index. Brazilian Journal of Medical and Biological Research, 43, 1116-1122. http://dx.doi.org/10.1590/S0100-879X2010007500103

[15] Charnsangavej, C., Clary, B., Fong, Y., Grothey, A., Pawlik, T.M. and Choti, M.A. (2006) Selection of Patients for Resection of Hepatic Colorectal Metastases: Expert Consensus Statement. Annals of Surgical Oncology, 13, 1261-1268. http://dx.doi.org/10.1245/s10434-006-9023-y

[16] Malik, H.Z., Prasad, R., Halazun, K.J., Aldoori, A., Al-Mukhtar, A., Gomez, D., et al. (2007) Preoperative Prognostic Score for Predicting Survival after Hepatic Resection for Colorectal Liver Metastases. Annals of Surgery, 246, 806-814. http://dx.doi.org/10.1097/SLA.0b013e318142d964

[17] Zakaria, S., Donohue, J.H., Que, F.G., Farnell, M.B., Schleck, C.D., Ilstrup, D.M. and Nagorney, D.M. (2007) Hepatic Resection for Colorectal Metastases: Value for Risk Scoring Systems? Annals of Surgery, 246, 183-191. http://dx.doi.org/10.1097/sla.0b013e3180603039

[18] Kishi, Y., Kopetz, S., Chun, Y.S., Palavecino, M., Abdalla, E.K. and Vauthey, J.-N. (2009) Blood Neutrophil-toLymphocyte Ratio Predicts Survival in Patients with Colorectal Liver Metastases Treated with Systemic Chemotherapy. Annals of Surgical Oncology, 16, 614-622. http://dx.doi.org/10.1245/s10434-008-0267-6

[19] Mitsuyama, Y., Shiba, H., Haruki, K., Fujiwara, Y., Furukawa, K., Iida, T., et al. (2012) Carcinoembryonic Antigen and Carbohydrate Antigen 19-9 Are Prognostic Predictors of Colorectal Cancer with Unresectable Liver Metastasis. Oncology Letters, 3, 767-771.

[20] Nagakura, S., Shirai, Y., Yokoyama, N., Wakai, T., Suda, T. and Hatakeyama, K. (2003) Major Hepatic Resection Reduces the Probability of Intrahepatic Recurrences Following Resection of Colorectal Carcinoma Liver Metastases. Hepatogastroenterology, 50, 779-783.

[21] John, S.K., Robinson, S.M., Rehman, S., Harrison, B., Vallance, A., French, J.J., et al. (2013) prognostic Factors and Survival after Resection of Colorectal Liver Metastasis in the Era of Preoperative Chemotherapy: An 11-Year Sin- 
gle-Centre Study. Digestive Surgery, 30, 293-301. http://dx.doi.org/10.1159/000354310

[22] Marti, J., Modolo, M.M., Fuster, J., Comas, J., Cosa, R., Ferrer, J., et al. (2009) Prognostic Factors and Time-Related Changes Influence Results of Colorectal Liver Metastases Surgical Treatment: A Single-Center Analysis. World Journal of Gastroenterology, 15, 2587-2594. http://dx.doi.org/10.3748/wjg.15.2587

[23] Donadon, M., Ribero, D., Morris-Stiff, G., Abdalla, E.K. and Vauthey, J.N. (2007) New Paradigm in the Management of Liver-Only Metastases from Colorectal Cancer. Gastrointestinal Cancer Research, 1, 20-27.

[24] Aloia, T.A., Vauthey, J.N., Loyer, E.M., Ribero, D., Pawlik, T.M., Wei, S.H., et al. (2006) Solitary Colorectal Liver Metastasis: Resection Determines Outcome. Archives of Surgery, 141, 460-466. http://dx.doi.org/10.1001/archsurg.141.5.460

[25] Fernandez, F.G., Drebin, J.A., Linehan, D.C., Dehdashti, F., Siegel, B.A. and Strasberg, S.M. (2004) Five-Year Survival after Resection of Hepatic Metastases from Colorectal Cancer in Patients Screened by Positron Emission Tomography with F-18 Fluorodeoxyglucose (FDG-PET). Annals of Surgery, 240, 438-447. http://dx.doi.org/10.1097/01.sla.0000138076.72547.b1

[26] Lee, W.S., Yun, S.H., Chun, H.K., Lee, W.Y., Kim, S.J., Choi, S.H., et al. (2008) Clinical Outcomes of Hepatic Resection and Radiofrequency Ablation in Patients with Solitary Colorectal Liver Metastasis. Journal of Clinical Gastroenterology, 42, 945-949. http://dx.doi.org/10.1097/MCG.0b013e318064e752

[27] Lordan, J.T., Riga, A., Worthington, T.R. and Karanjia, N.D. (2009) Early and Long-Term Outcomes of Patients Undergoing Liver Resection and Diaphragm Excision for Advanced Colorectal Liver Metastases. Annals of The Royal College of Surgeons of England, 91, 483-488. http://dx.doi.org/10.1308/rcsann.2009.91.6.483

[28] Nikfarjam, M., Shereef, S., Kimchi, E.T., Gusani, N.J., Jiang, Y.X., Avella, D.M., et al. (2009) Survival Outcomes of Patients with Colorectal Liver Metastases Following Hepatic Resection or Ablation in the Era of Effective Chemotherapy. Annals of Surgical Oncology, 16, 1860-1867. http://dx.doi.org/10.1245/s10434-008-0225-3

[29] Choti, M.A., Sitzmann, J.V., Tiburi, M.F., Sumetchotimetha, W., Rangsin, R., Schulick, R.D., et al. (2002) Trends in Long-Term Survival Following Liver Resection for Hepatic Colorectal Metastases. Annals of Surgery, 235, 759-766. http://dx.doi.org/10.1097/00000658-200206000-00002

[30] Chang, A.E. and Skibber, J.M. (2006) Evaluation of Tumour Markers: An Evidence-Based Guide for Determination of Clinical Utility. In: Chang, A.E., Ed., Oncology: An Evidence-Based Approach, 1st Edition, Springer, New York, 1753-1767. http://dx.doi.org/10.1007/0-387-31056-8

[31] Gion, M., Mione, R., Barioli, P. and Dittadi, R. (1996) Dynamic Use of Tumor Marker, Rationale-Clinical Applications and Pitfalls. Anticancer Research, 16, 2279-2284.

[32] Spolverato, G., Ejaz, A., Azad, N. and Pawlik, T.M. (2013) Surgery for Colorectal Liver Metastases: The Evolution of Determining Prognosis. World Journal of Gastrointestinal Oncology, 5, 207-221. http://dx.doi.org/10.4251/wjgo.v5.i12.207

[33] Nordlinger, B., Guiguet, M., Vaillant, J.C., Balladur, P., Boudjema, K., Bachellier, P., Jaeck, D. and Association Française de Chirurgie (1996) Surgical Resection of Colorectal Carcinoma Metastases to the Liver. A Prognostic Scoring System to Improve Case Selection, Based on 1568 Patients. Cancer, 77, 1254-1262. http://dx.doi.org/10.1002/(SICI)1097-0142(19960401)77:7<1254::AID-CNCR5>3.0.CO;2-I

[34] Arru, M., Aldrighetti, L., Castoldi, R., Di Palo, S., Orsenigo, E., Stella, M., Pulitanò, C., Gavazzi, F., Ferla, G., Di Carlo, V. and Staudacher, C. (2008) Analysis of Prognostic Factors Influencing Long-Term Survival after Hepatic Resection for Metastatic Colorectal Cancer. World Journal of Surgery, 32, 93-103. http://dx.doi.org/10.1007/s00268-007-9285-y

[35] Merkel, S., Bialecki, D., Meyer, T., Müller, V., Papadopoulos, T. and Hohenberger, W. (2009) Comparison of Clinical Risk Scores Predicting Prognosis after Resection of Colorectal Liver Metastases. Journal of Surgical Oncology, 100, 349-357. http://dx.doi.org/10.1002/jso.21346

[36] Reissfelder, C., Rahbari, N.N., Koch, M., Ulrich, A., Pfeilschifter, I., Waltert, A., Müller, S.A., Schemmer, P., Büchler, M.W. and Weitz, J. (2009) Validation of Prognostic Scoring Systems for Patients Undergoing Resection of Colorectal Cancer Liver Metastases. Annals of Surgical Oncology, 16, 3279-3288. http://dx.doi.org/10.1245/s10434-009-0654-7

[37] Nathan, H., de Jong, M.C., Pulitano, C., Ribero, D., Strub, J., Mentha, G., Gigot, J.F., Schulick, R.D., Choti, M.A., Aldrighetti, L., et al. (2010) Conditional Survival after Surgical Resection of Colorectal Liver Metastasis: An International Multi-Institutional Analysis of 949 Patients. Journal of the American College of Surgeons, 210, 755-764. http://dx.doi.org/10.1016/j.jamcollsurg.2009.12.041

[38] Liska, V., Holubec, L., Treska, V., Skalicky, T., Sutnar, A. and Kormunda, S. (2007) Dynamics of Serum Levels of Tumour Markers and Prognosis of Recurrence and Survival after Liver Surgery for Colorectal Liver Metastases. Anticancer Research, 27, 2861-2864.

[39] Park, J.W., Chang, H.J., Kim, B.C., Yeo, H.Y. and Kim, D.Y. (2013) Clinical Validity of Tissue Carcinoembryonic 
Antigen Expression as Ancillary to Serum Carcinoembryonic Antigen Concentration in Patients Curatively Resected for Colorectal Cancer. Colorectal Disease, 15, e503-e511.

\section{List of Abbreviations}

CA 19-9 - carbohydrate antigen 19-9

CEA-carcinoembryonic antigen

CRC - colorectal carcinoma

SPSS21-Statistical Package for the Social Sciences 21

TK-thymidine kinase

TPA - tissue polypeptide antigen

TPS - tissue polypeptide-specific antigen

UNACIR HPB - Association of Hepatopancreatobiliary Surgery in San Isidro, Provence of Buenos Aires, Argentina 